\title{
Fabrication of PTFE/Nomex fabric/phenolic composites using a layer-by-layer self-assembly method for tribology field application
}

\author{
Mingming YANG ${ }^{1}$, Zhaozhu ZHANG ${ }^{1, *}$, Junya YUAN ${ }^{1,2}$, Liangfei WU ${ }^{1,2}$, Xin ZHAO $^{1}$, Fang GUO $^{1, *}$, Xuehu MEN ${ }^{3}$, \\ Weimin LIU ${ }^{1}$ \\ ${ }^{1}$ State Key Laboratory of Solid Lubrication, Lanzhou Institute of Chemical Physics, Chinese Academy of Sciences, Lanzhou 730000, China \\ ${ }^{2}$ University of Chinese Academy of Sciences, Beijing 100039, China \\ ${ }^{3}$ School of Physical Science and Technology, Lanzhou University, Lanzhou 730000, China \\ Received: 10 August 2018 / Revised: 20 November 2018 / Accepted: 28 November 2018 \\ (C) The author(s) 2019.
}

\begin{abstract}
Fabric composites are widely applied as self-lubricating liner for radial spherical plain bearings owing to their excellent mechanical and tribological properties. Nevertheless, the poor interfacial strength between fibers and the resin matrix limits the performance of composites utilized as tribo-materials. To overcome this drawback, a mild layer-by-layer (LbL) self-assembly method was successfully used to construct hybrid fabric composites in the present work. In addition, this investigation addressed the effect of self-assembly cycles on the friction and wear behaviors of hybrid fabric composites under dry sliding condition. The results demonstrate that fabric composites with three or more self-assembly cycles have significantly enhanced surface activities and anti-wear performances. The results obtained in this work can provide guidance in the preparation of selflubricating liner composites and highlight how the LbL self-assembly techniques could influence the properties of hybrid fabric composites.
\end{abstract}

Keywords: LbL self-assembly; hybrid fabric; wear; friction

\section{Introduction}

Because of high load carrying capacities, maneuverability and maintenance-free properties, self-lubricating bearings are widely applied in aerospace, trains, marine and power generation [1-3]. In general, self-lubricating bearings incorporate three components-a metal inner ring, an outer race, and a self-lubricating liner between them. The life-span and stability of self-lubricating bearings during sliding processes are significantly influenced by the self-lubricating materials that constitute the liner. Among different candidate materials, hybrid fabric/polymer composites have been extensively utilized as self-lubricating liners, owing to outstanding chemical resistance, light weights and self-lubrication properties especially under dry sliding conditions
[4-6]. The self-lubricating fabrics are produced by a weaving process. PTFE and aramid fibers are usually included in a two-layer warp fabric, as they possess the high specific strength of Nomex fibers and outstanding self-lubrication properties of PTFE fibers [7-9]. Furthermore, phenolic are widely used as adhesive in such composites. The performance of composites utilized as tribo-materials is highly influenced by the efficiency of the friction stress transference between the phenolic matrix and the self-lubricating fabric. However, the fiber-phenolic resin interface adhesion strength is rather weak because of the intrinsically smooth surfaces and inert chemical structure of weaving fibers. Hence, surface modification of hybrid fabrics is vital. Numerous approaches, such as plasma treatment, chemical grafting and whiskerization,

* Corresponding authors: Zhaozhu ZHANG, E-mail: zzzhang@licp.cas.cn; Fang GUO, E-mail: guofang@licp.cas.cn 
have been utilized to change the surface properties of high-performance fibers for fabric reinforced polymer matrix composites [10-12]. Nevertheless, with the increasing demands for high-performance tribomaterials in industries, single surface modification of hybrid fabrics is no longer sufficient.

Layer-by-layer ( $\mathrm{LbL}$ ) methods have been widely applied for construction uniform films in the fields of interfacial modification, separation, drug delivery, among others [13-15]. Traditionally, LbL assembly was carried out sequentially adsorbing oppositely charged materials onto a substrate. Zhou et al. [16] introduced $\mathrm{MgAlFe}$ layered double hydroxide (LDH) and $\mathrm{SiO}_{2}$ onto the surface of aramid by a green LbL self-assembly method, which resulted in improvements in the surface activity and UV resistance of composites. Yu et al. [17] showed that the flame retardancy of the LbL modified Ramie fabric reinforced unsaturated polyester resin composites was improved by increasing the $\mathrm{LbL}$ assembly cycles. This was primarily attributed to the early decomposition of the LbL coating on the fabric.

Furthermore, the incorporation of functional fillers was shown to be effective in improving the friction and wear properties of hybrid fabric liner composites [18-19]. Two-dimensional (2D) nano-sheets, consisting of single or few atomic layers, such as graphene oxide (GO), molybdenum disulfide $\left(\mathrm{MoS}_{2}\right)$, graphitic carbon nitride $\left(\mathrm{g}-\mathrm{C}_{3} \mathrm{~N}_{4}\right)$, boron nitride, have gained considerable attention owing to their excellent performances when utilized solely or in composites form [20-22]. Among these 2D nano-materials, GO has superior physical structural properties while at the same time, possessing numerous functional groups in the edges that can provide active sites for further surface modification [23].

Therefore, the aim of this study is to improve the interfacial activity of hybrid fabric and simultaneously anchor GOs on fibers surfaces using a mild and green LbL method. Specifically, GO/PAMPA and PDDA were alternately self-assembled on the surfaces of hybrid fabrics. X-ray powder diffraction (XRD), Raman spectroscopy, X-ray photoelectron spectroscopy (XPS) and scanning electron microscopy (SEM) results are used to prove the formation of even GO coatings on PTFE and Nomex fiber surfaces using LbL selfassembly techniques and significant enhancement in the wettability of the lubricating and bonding surface.
Moreover, the wear mechanisms are examined based on the characteristics of the worn surfaces of hybrid fabric composites and steel counterpart pin.

\section{Experimental}

\subsection{Materials}

PTFE and Nomex fibers were purchased from DuPont Plant. The volume ratio of PTFE to Nomex in fabric is 1:3. Poly (2-acrylamido-2-methyl-1-propane sulfonic acid) solution (PAMPA, $M_{\mathrm{W}}=2000000,15 \mathrm{wt} \%$ in $\mathrm{H}_{2} \mathrm{O}$ ) was purchased from Sigma-Aldrich, while poly (diallyl ammonium Chloride) solution (PDDA, $M_{\mathrm{W}}=1000000$, $35 \mathrm{wt} \%$ in $\mathrm{H}_{2} \mathrm{O}$ ) was purchased from Meryer Chemical Technology Co., Ltd. Graphene oxide (GO) was provided by Nanjing XFNANO Materials Tech Co., Ltd, China. The adhesive resin was provided by Shanghai Xing-Guang Chemical Plant (China).

\subsection{Characterizations}

XRD analysis was performed on an XRD system (Philips Corp., The Netherlands), operating with $\mathrm{Cu}-\mathrm{K}$ radiation at a scanning rate of $0.5^{\circ}$ per second over a $2 \theta$ range of $10^{\circ}$ to $80^{\circ}$. Raman spectroscopy (in a LabRAM HR800 system with $532 \mathrm{~nm}$ laser excitation), was employed to characterize the structural features of the LbL modified hybrid fabric. The surface morphology and microstructure of graphene oxide and hybrid fabric were observed using field emission scanning electron microscopy (FE-SEM, JSM-6701F, JEOL, Japan). The morphologies of the worn surfaces of the composites and their counterpart steel pins were analyzed on a JSM-5600LV scanning electron microscope (SEM). X-ray photoelectron spectroscopy (XPS) measurements were conducted on a VGESCALAB210 spectrometer. A drop-shaped analyzer (KrüssDSA100, Krüss Company, Ltd., Germany) was used to measure the contact angle (CA) of water droplets $(5 \mu \mathrm{L})$ at ambient temperature. The tribological properties were studied using Xuanwu-III friction and wear tester.

\subsection{Preparation of LbL modified PTFE/Nomex fabric and composites}

To enhance the charges on the fiber surface, the 
PTFE/Nomex fabric was treated with air-plasma ( $30 \mathrm{~W}, 5 \mathrm{~min}$ ) and dipped into a dispersion containing $0.1 \mathrm{wt} \%$ negatively charged PAMPA and $0.1 \mathrm{wt} \%$ GO solution at PH 10, for $10 \mathrm{~min}$. Subsequently, the hybrid fabric was rinsed with distilled water and then dried in an oven at $80{ }^{\circ} \mathrm{C}$. The obtained fabric was then dipped into the PDDA solution at $\mathrm{pH} 10$ for $10 \mathrm{~min}$, washed with distilled water and dried in an oven at $80{ }^{\circ} \mathrm{C}$. This process is regarded as one self-assembly cycle, and the resultant fabric is coded as a LbL-fabric. The process was repeated $n$ times to obtain different fabrics with different number of self-assembly cycles, designated as LbL-n-fabric $(n=3,6,9,12)$. The fabric/phenolic composites were fabricated based on the method used in our previous work [18].

\section{Results and discussion}

\subsection{LbL film modified hybrid fabric (LbL-fabric) characterization}

The structures of the virgin fabric, LbL-6-fabric and GO were examined by XRD. Figure 1(a) shows the XRD pattern of the virgin fabric. The occurrence of a highly eminent peak located around the $18.2^{\circ}$ region, is consistent with the high crystallinity of PTFE fibers [23]. The XRD pattern of the Nomex fibers displays two relatively lower intensity peaks at around $23.52^{\circ}$ and $27.33^{\circ}$ which is consistent with its reported values [24]. Compared to the virgin fabric, the intensity of the diffraction peaks for the LbL-6-fabric obviously reduced. This is attributable mainly to the GO on the fiber surfaces (see Fig. 1(b)). Figure 1(c) illustrates the XRD spectrum of the GO. A typical single strong peak [25] appeared at approximately $11.35^{\circ}$. Because the XRD signal of the PTFE fibers is very intense and only a small amount of GO is anchored on the fiber surface, the surface changes of LbL-6-fabric is difficult to examine using this technique.

Raman spectroscopy was adopted to investigate the structure of the lubrication and bonding surface of the hybrid fabric. Figure 2 shows the Raman spectra of the virgin and LbL-6-fabric. In the Raman spectra of the virgin fabric (Fig. 2(a)), the weak peaks at $278 \mathrm{~cm}^{-1}$ and $1,304 \mathrm{~cm}^{-1}$ correspond to the different modes of the $\mathrm{CF}_{2}$ groups [23], while the strongest peaks centered at $1,000 \mathrm{~cm}^{-1}, 1,250 \mathrm{~cm}^{-1}, 1,339 \mathrm{~cm}^{-1}, 1,542 \mathrm{~cm}^{-1}$ and $1,602 \mathrm{~cm}^{-1}$ correspond to the $\mathrm{C}-\mathrm{C}$ bands in the aromatic
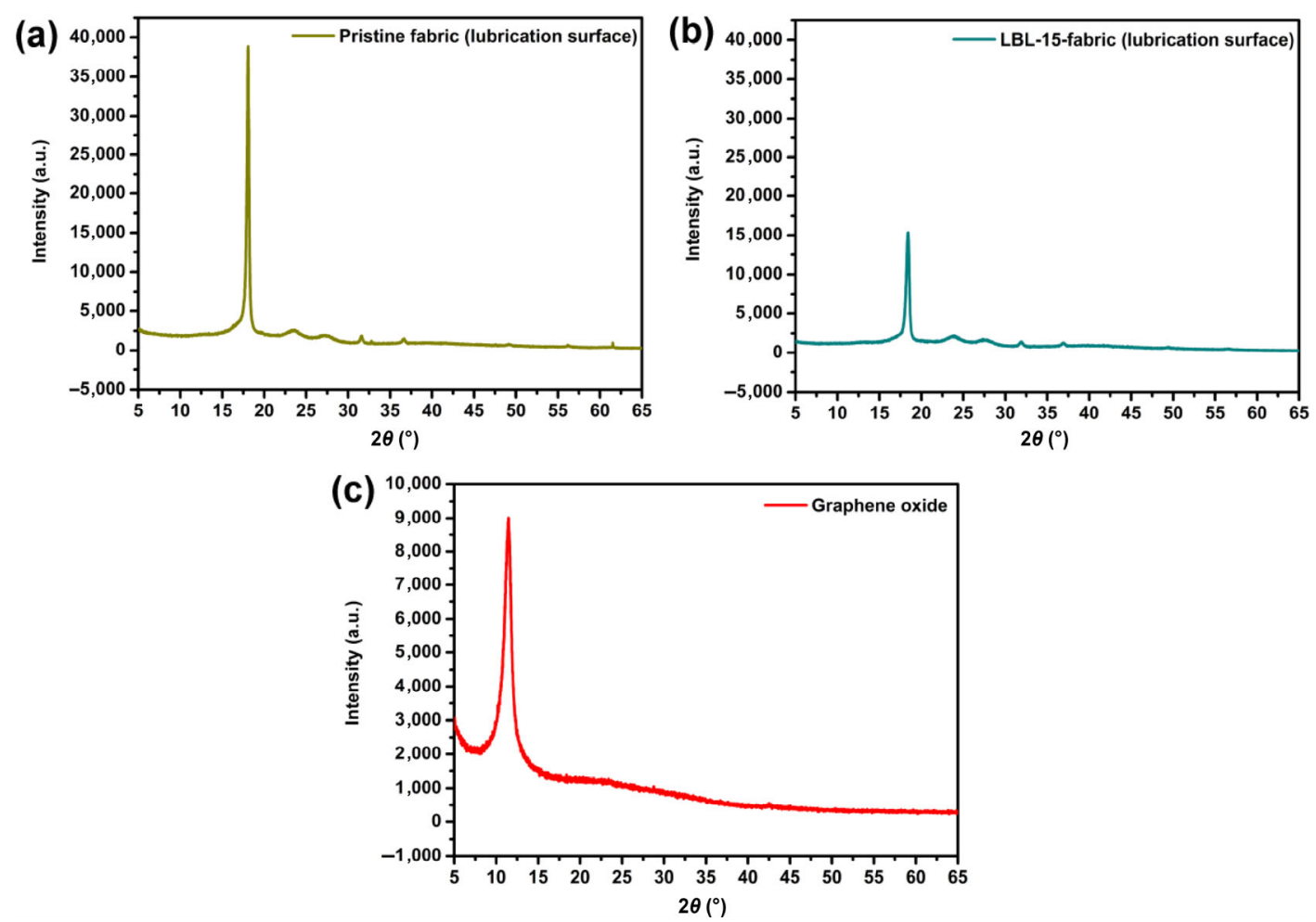

Fig. 1 XRD patterns: (a) virgin fabric; (b) LbL-6-fabric; (c) graphene oxide. 

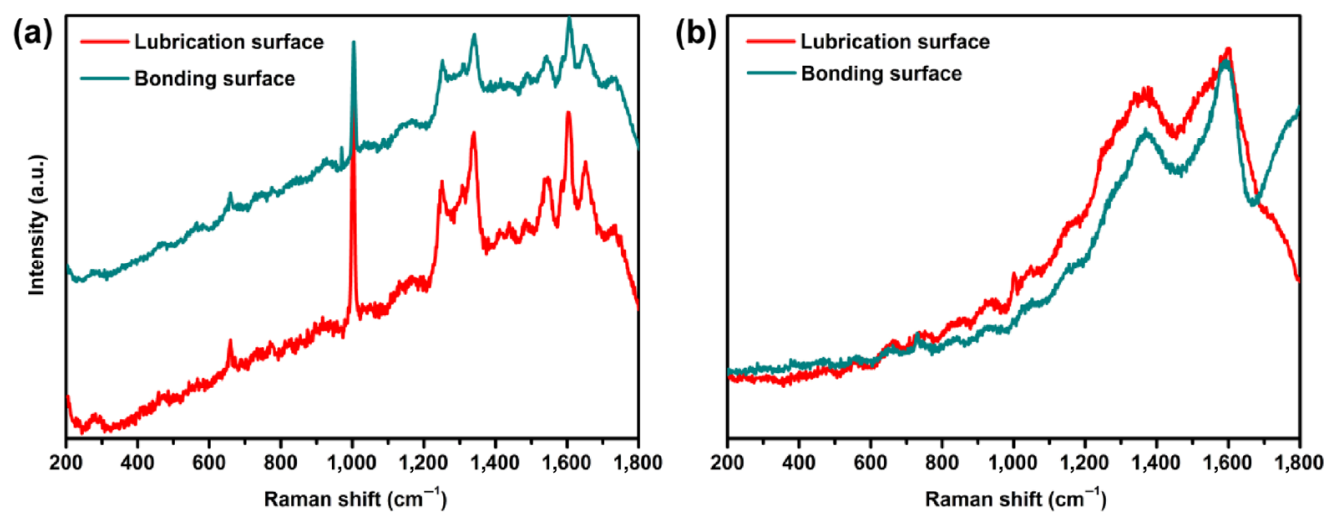

Fig. 2 Raman spectra: (a) virgin fabric; (b) LbL-6-fabric.

rings of Nomex fibers [24]. The vibration at 1,649 $\mathrm{cm}^{-1}$ position is attributable to the band of $\mathrm{C}=\mathrm{O}$ group in the main fiber structure of Nomex. However, nearly all distinctive peaks of the PTFE and Nomex fibers disappear when the hybrid fabric is modified by the LbL technique (GO/ PAMPA/PDDA) (see Fig. 2(b)). Two new broad peaks appear at $1,362 \mathrm{~cm}^{-1}$ and $1,590 \mathrm{~cm}^{-1}$ and correspond to the D and $G$ bonds of GO, respectively. This result suggests that the GO have been successfully deposited on fibers surfaces.

To confirm the above statement, XPS spectra of the virgin and LbL-6-fabrics were obtained. The virgin fabric spectra of Fig. 3(a) show four bands, which are correspond to C1s, N1s, O1s and F1s at $283 \mathrm{eV}, 400 \mathrm{eV}$, $529 \mathrm{eV}$ and $689 \mathrm{eV}$, respectively. The F1s band of the LbL-6-fabric disappear, a situation attributable mainly to the lower fraction of PTFE in the hybrid fabric (PTFE to Nomex volume ratio is: 1:3). Two high intensity peaks at $283 \mathrm{eV}$ and $529 \mathrm{eV}$ (Fig. 3(b)) are attributable to $\mathrm{C} 1 \mathrm{~s}$ and $\mathrm{O} 1 \mathrm{~s}$, respectively. However, for LbL-6-fabric, small band assigned to $\mathrm{S} 2 \mathrm{p}$ at $167 \mathrm{eV}$ is observed, suggesting that PAMPA exists on the surfaces of the LbL-6-fabric.

The morphologies of the Nomex and PTFE fiber surfaces were observed by SEM. As shown in Figs. 4(a) and $4(\mathrm{~d})$, the surfaces of the as-received Nomex and PTFE fibers exhibit relatively clean and smooth morphologies. While the LbL-6-Nomex fiber (Figs. 4(b) and 4(c)) presents a highly homogeneous distribution of GO over the Nomex surfaces, the GO distribution is less-homogeneous, for the LbL-6-PTFE fiber, owing to the extremely smooth and low surface energy of the PTFE surface. These results are in agreement with the Raman spectroscopy and XPS results. Figures $4(\mathrm{~g})-4$ (i) show the contact angles of the virgin and LbL-6-fabric. It can be seen that the contact angle of the lubricating and bonding surfaces of the virgin fabric is $117.4^{\circ}$ and $104.8^{\circ}$, respectively (see Figs. $4(\mathrm{~g}$ ) and $4(\mathrm{~h})$ ). On the contrary, the lubricating and bonding surfaces of the LbL-6-fabric exhibited superhydrophilicity, which suggests that the LbL-6-fabric has excellent wettability. Previous work [26], has shown
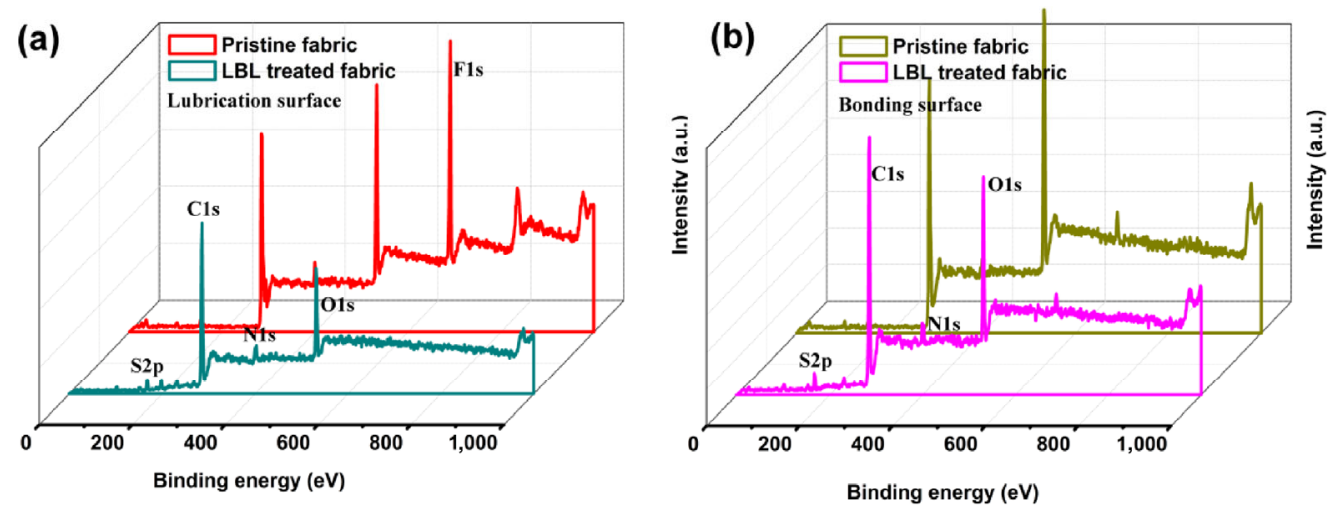

Fig. 3 XPS spectra: (a) virgin fabric; (b) LbL-6-fabric. 


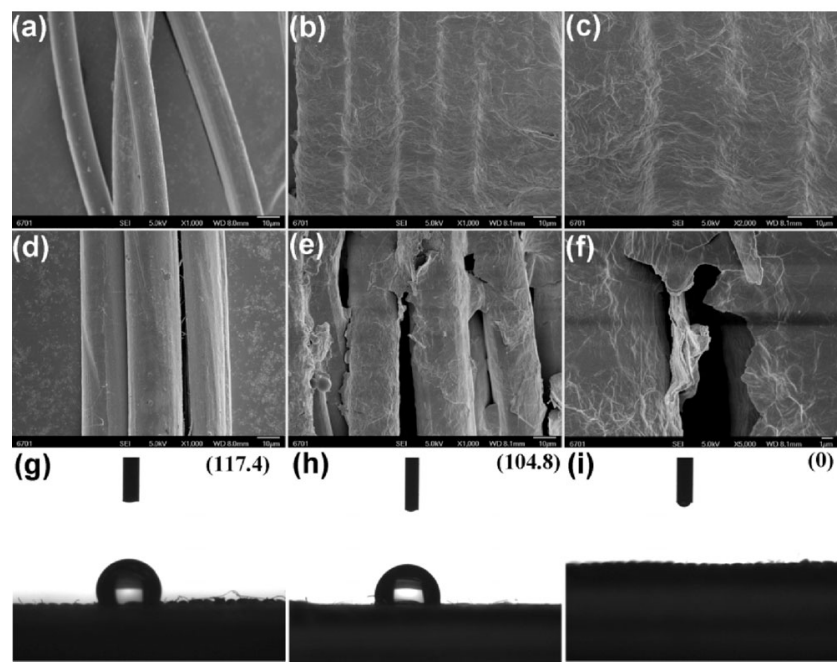

Fig. 4 SEM images of virgin fibers (a) Nomex, (b-c) LbL-6Nomex fibers, (d) PTFE, (e-f) LbL-6-PTFE fibers, respectively; The photo of CA: (g) lubricating surface of virgin fabric, (h) bonding surface of virgin fabric, (i) LbL-6-fabric.

that outstanding wettability is beneficial to enhancing the interfacial strength between fibers and resin matrices [26].

\subsection{The influence of LbL modification on tribological properties of hybrid fabric composites}

Figure 5 shows the friction and wear properties of virgin fabric and LbL-n-fabric composites, including friction coefficients and wear rates. As can be seen from Fig. 5(a), the friction coefficient of fabric composites increases with the number of self-assembly cycles, until a limiting point after which it decrease. Like in previous work [27], the addition of GO does not reduce the friction coefficient of the hybrid fabric composite, while obviously improving the wear resistance. The LbL self-assembly increased the friction coefficient from 0.0778 to 0.137 , whereas the wear rate was significantly reduced from 1.231 to 0.551 .

Figure 6 shows the SEM morphologies of the worn surfaces of hybrid fabric composites sliding against the counterpart pin at $70 \mathrm{MPa}$ and $0.26 \mathrm{~m} / \mathrm{s}$. As seen from Figs. 6(a) and 6(e), numerous broken fibers protrude from the worn surfaces of the virgin fabric composite, in addition to the abundant wear debris, distributed around them. These situations indicate that the interfacial bonding strength between the fibers and the phenolic resin matrix is weak. For the LbL-3 hybrid fabric composite, the worn surfaces are relatively smooth with few fiber pull-outs and wear debris on the surface (Fig. 6(b)). Fiber thinning indicates that the interfacial bonding strength between the fibers and the phenolic resin matrix increase after polyelectrolytes and graphene oxide (on a layer by layer basis), were assembled on the hybrid fabric surfaces (Fig. 6(f)). However, the worn surfaces of the LbL-6 fabric composite show evidently different surface morphologies. In comparison with the virgin fabric composite, the LbL-6-fabric is well entrapped in the phenolic resin matrix owing to the deposition of graphene oxide on the fiber surface by the LbL method. As seen from Figs. 6(c) and 6(g), broken fibers and wear debris on the worn surfaces of the LbL-6-fabric composite are clearly reduced owing the improvement in interfacial bonding strength. Figures $6(\mathrm{~d})$ and $6(\mathrm{~h})$ shows the worn surfaces of the LbL-12-fabric composite. In this case, however, many phenolic resins are observed to peel off and numerous fibersare exposed and broken, which demonstrates that the tribological behaviors of hybrid fabric composites do not improve beyond a certain limit, as the number of
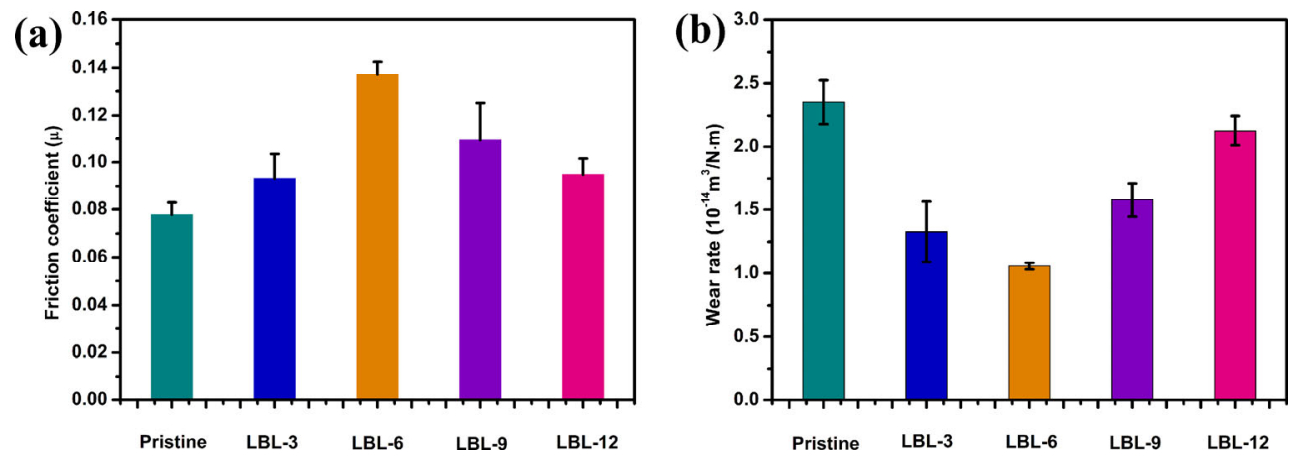

Fig. 5 Friction coefficient (a) and wear rate (b) of hybrid fabric/phenolic composite as a function of layer-by-layer self-assembly cycles $(70 \mathrm{MPa}, 0.26 \mathrm{~m} / \mathrm{s})$. 

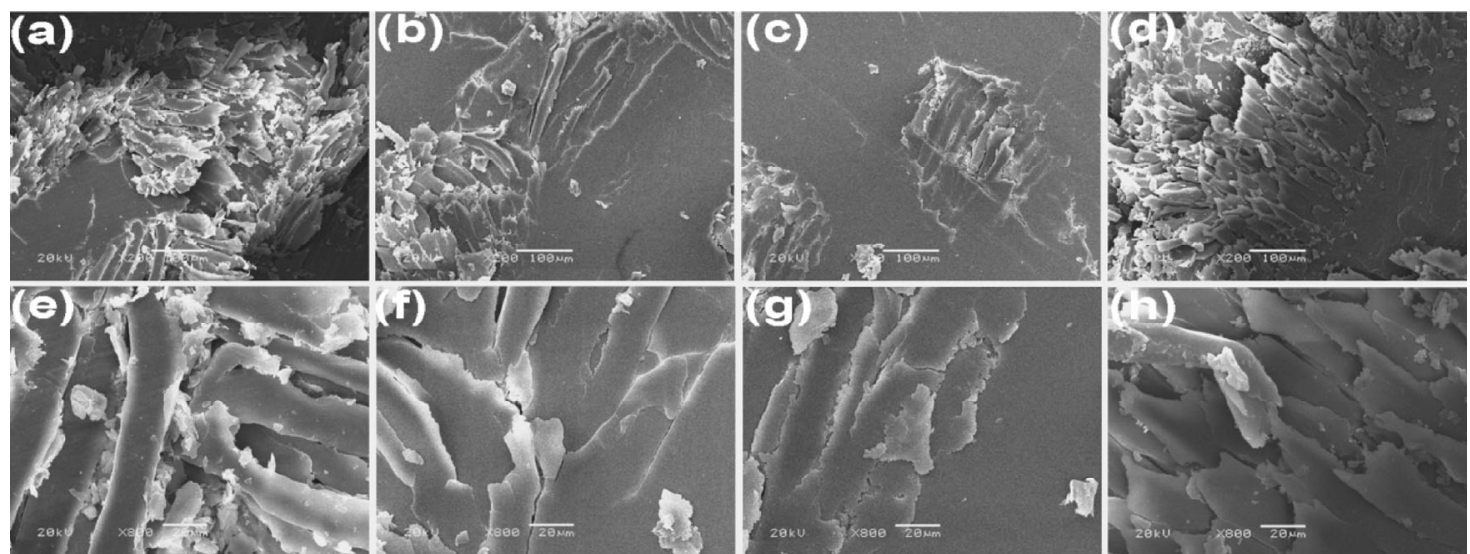

Fig. 6 SEM images of the worn surfaces of hybrid fabric/phenolic composites: (a) virgin composite, (b) LbL-3-fabric composite, (c) LbL-6-fabric composite, (d) LbL-12-fabric composite, (e-f) the magnified images of (a-d), respectively.

LBL self-assembly cycles is increased.

It has been proven by numerous reports that the transfer film formed on counterpart pin surfaces plays a vital role in the tribological properties of polymer matrix composites. In general, high-quality transfer films can prevent or reduce the direct contact between polymer matrix composites and steel counterpart pins. This results in excellent tribological properties. Hence, the morphologies of the counterpart pin surfaces after sliding against the virgin and LbL-6 hybrid fabric composites are shown in Fig. 7. It can be seen from Fig. 7(a) that the transfer film of the virgin composite seems to be lumpy, discontinuous and easily shelled off from the counterpart pin surfaces. Besides, numerous wear debris and furrows are observed on the surface of the counterpart pin, which indicates that the virgin hybrid fabric composite underwent severe wear. However, the incorporation of GO and self-assembly polyelectrolytes by the LbL method into the hybrid fabric composite leads to the formation of a highquality transfer film. The transfer films formed on the counterpart pin surface were highly homogeneous and continuous (see Fig. 7(b)). Furthermore, Raman spectra analyses proved that the transfer film of the LbL-6 hybrid fabric composite contains GO. It is worth noting that the two prominent peaks at $1,365 \mathrm{~cm}^{-1}$ and $1,611 \mathrm{~cm}^{-1}$ correspond to the D and $G$ bonds of GO, respectively (see Fig. 8). Hence, it can be concluded that adding GO to the hybrid fabric composite contributed to forming a homogeneous and continuous transfer film on the counterpart pin surface.

\section{Conclusions}

In summary, the hybrid fabric was modified using a green and mild LbL method, which only influences the chemical composition and morphology of the fiber surfaces. Besides, the effects of the LbL self-assembly cycles on the tribological performances of hybrid fabric/ phenolic composites were systematically investigated. The characterization results demonstrate that GO
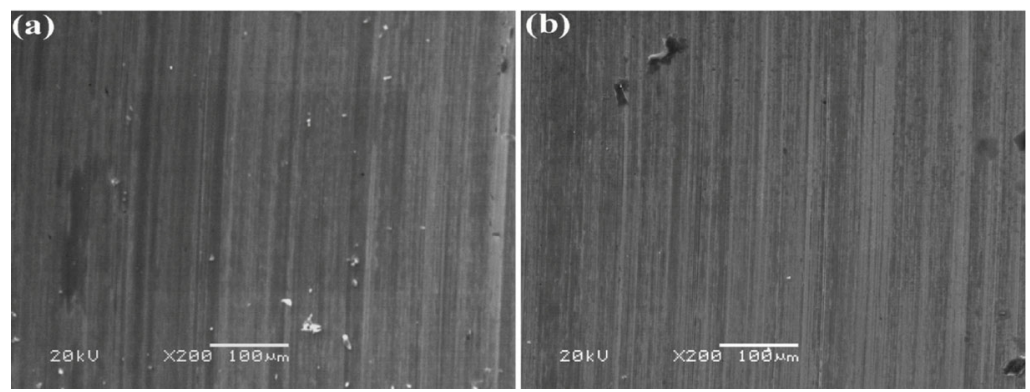

Fig. 7 SEM images of the worn surfaces of counterpart pin sliding against hybrid fabric composite: (a) virgin, and (b) LbL-6-fabric composite. 


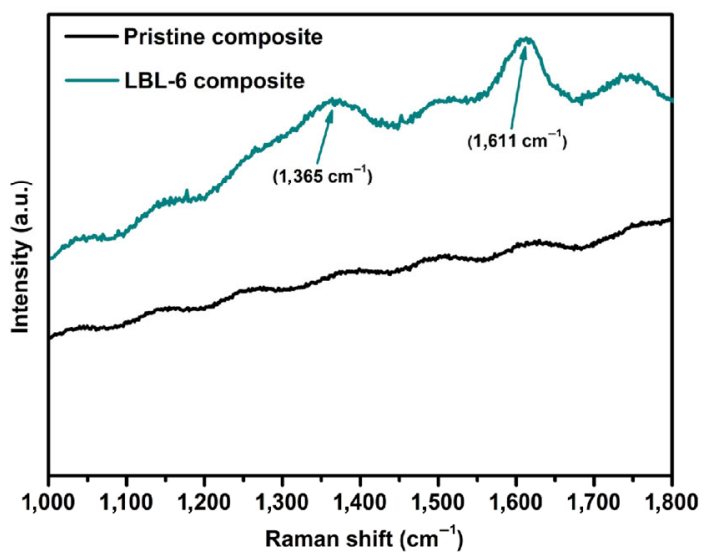

Fig. 8 Raman spectra of the steel counterpart pin surface.

successfully anchors on hybrid fabric surfaces and significantly improves the surface wettability. The wear rate significantly reduces when the hybrid fabric is modified using the LbL self-assembly technique. Sliding wear tests indicate that LbL-6-hybrid fabric/phenolic composites exhibit the lowest wear rate. Moreover, a smooth and uniform transfer film is formed on the counterpart pin after sliding against the LbL-6-hybrid fabric composite.

\section{Acknowledgements}

This work was supported by the National Nature Science Foundation of China (Nos. 51805516 and 51675252).

Open Access: This article is licensed under a Creative Commons Attribution 4.0 International Li-cense, which permits use, sharing, adaptation, distribution and reproduction in any medium or for-mat, as long as you give appropriate credit to the original author(s) and the source, provide a link to the Creative Commons licence, and indicate if changes were made.

The images or other third party material in this article are included in the article's Creative Commons licence, unless indicated otherwise in a credit line to the material. If material is not in-cluded in the article's Creative Commons licence and your intended use is not permitted by statuto-ry regulation or exceeds the permitted use, you will need to obtain permission directly from the copyright holder. To view a copy of this licence, visit http://creativecommons.org/licenses/ by $/ 4.0 /$.

\section{References}

[1] Aguirrebeitia J, Abasolo M, Vallejo J, Coria I, Heras I. Methodology for the assessment of equivalent load for selflubricating radial spherical plain bearings under combined load. Tribol Int 105: 69-76 (2017)

[2] Wang Z Q, Ni J, Gao D R. Combined effect of the use of carbon fiber and seawater and the molecular structure on the tribological behavior of polymer materials. Friction 6(2): 183-194 (2018)

[3] Chen Z Y, Yan H X, Liu T Y, Niu S. Nanosheets of $\mathrm{MoS}_{2}$ and reduced graphene oxide as hybrid fillers improved the mechanical and tribological properties of bismaleimide composites. Comp Sci Technol 125: 47-54 (2016)

[4] Song F Z, Wang Q H, Wang T M. High mechanical and tribological performance of polyimide nanocomposites reinforced by chopped carbon fibers in adverse operating conditions. Comp Sci Technol 134: 251-257 (2016)

[5] Qiu M, Yang Z P, Lu J J, Li Y C, Zhou D W. Influence of step load on tribological properties of self-lubricating radial spherical plain bearings with PTFE fabric liner. Tribol Int 113: 344-353 (2017)

[6] Gu D P, Duan C S, Fan B L, Chen S W, Yang Y L. Tribological properties of hybrid PTFE/Kevlar fabric composite in vacuum. Tribol Int 103: 423-431 (2016)

[7] Lu J J, Qiu M, Li Y C. Wear models and mechanical analysis of PTFE/Kevlar fabric woven liners used in radial spherical plain bearings. Wear 364-365: 57-72 (2016)

[8] Ren G N, Zhang Z Z, Zhu X T, Men X H, Jiang W, Liu W M. Sliding wear behaviors of Nomex fabric/phenolic composite under dry and water-bathed sliding conditions. Friction 2(3) 264-271 (2014)

[9] Yang S, Chalivendra V B, Kim Y K. Fracture and impact characterization of novel auxetic Kevlar $\AA /$ epoxy laminated composites. Comp Struct 168: 120-129 (2017)

[10] Hazarika A, Deka B K, Kim D Y, Roh H D, Park Y B, Park $\mathrm{H}$ W. Fabrication and synthesis of highly ordered nickel cobalt sulfide nanowire-grown woven Kevlar fiber/reduced graphene oxide/polyester composites. ACS Appl Mater Interfaces 9(41): 36311-36319 (2017)

[11] Zhang T, Jin J H, Yang S L, Li G, Jiang J M. Effect of hydrogen bonding on the compressive strength of dihydroxypoly(p-phenylenebenzobisoxazole) fibers. $A C S$ Appl Mater Interfaces 1(10): 2123-2125 (2009)

[12] Zhu X L, Yuan L, Liang G Z, Gu A J. Unique surface modified aramid fibers with improved flame retardancy, tensile properties, surface activity and UV-resistance through in situ formation of hyperbranched polysiloxane- $\mathrm{Ce}_{0.8} \mathrm{Ca}_{0.2} \mathrm{O}_{1.8}$ hybrids. J Mater Chem A 3(23): 12512-12529 (2015) 
[13] Richardson J J, Cui J W, Björnmalm M, Braunger J A, Ejima H, Caruso F. Innovation in layer-by-layer assembly. Chem Rev 116(23): 14828-14867 (2016)

[14] Whitesides G M, Grzybowski B. Self-assembly at all scales. Science 295(5564): 2418-2421 (2002)

[15] Deng B H, Shi Y F. Dynamic self-assembly of 'living' polymeric chains. Chem Phys Lett 668: 14-18 (2017)

[16] Zhou L F, Yuan L, Guan Q B, Gu A J, Liang G Z. Building unique surface structure on aramid fibers through a green layer-by-layer self-assembly technique to develop new high performance fibers with greatly improved surface activity, thermal resistance, mechanical properties and UV resistance. Appl Surf Sci 411: 34-45(2017)

[17] Yu X J, Pan Y, Wang D, Yuan B H, Song L, Hu Y. Fabrication and properties of biobased layer-by-layer coated ramie fabric-reinforced unsaturated polyester resin composites. Ind Eng Chem Res 56(16): 4758-4767 (2017)

[18] Yuan J Y, Zhang Z Z, Yang M M, Wang W J, Men X H, Liu W M. POSS grafted hybrid-fabric composites with a biomimic middle layer for simultaneously improved UV resistance and tribological properties. Comp Sci Technol 160: 69-78 (2018)

[19] Zhang C, Fei J, Qi Y, Luo L, Dong L S, Huang J F. TiO nanowires $/ \mathrm{TiO}_{2}$ film/woven carbon fiber ternary hybrid: Significant mechanical and wear-resisting properties of phenolic composite. Tribol Int 127: 129-137 (2018)

[20] Isarn I, Massagués L, Ramis X, Serra À, Ferrando F. New BN-epoxy composites obtained by thermal latent cationic curing with enhanced thermal conductivity. Comp Part $A$ Appl Sci Manuf 103: 35-47 (2017)

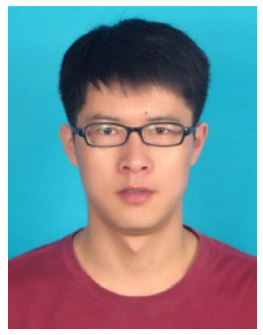

Mingming YANG. He is currently an assistant researcher at Lanzhou Institute of Chemical Physics, Chinese Academy Science. He received his bachelor degree in chemistry from Longdong University in 2012.

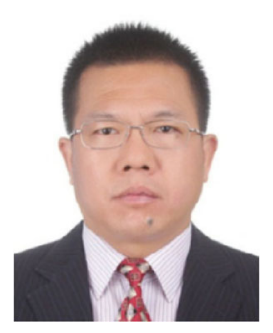

Zhaozhu ZHANG. He is currently a group leader at Lanzhou Institute of Chemical Physics, Chinese Academy Science. He received his $\mathrm{Ph} . \mathrm{D}$. degree from Lanzhou Institute of Chemical Physics in 1998. His
[21] Zhao H X, Yu H T, Quan X, Chen S, Zhang Y B, Zhao H M, Wang H. Fabrication of atomic single layer graphitic- $\mathrm{C}_{3} \mathrm{~N}_{4}$ and its high performance of photocatalytic disinfection under visible light irradiation. Appl Catal B Environ 152-153: 46-50 (2014)

[22] Han W B, Zhao G D, Zhang X H, Zhou S B, Wang P, An Y $\mathrm{M}, \mathrm{Xu}$ B S. Graphene oxide grafted carbon fiber reinforced siliconborocarbonitride ceramics with enhanced thermal stability. Carbon 95: 157-165 (2015)

[23] Wyszkowska E, Leśniak M, Kurpaska L, Prokopowicz R, Jozwik I, Sitarz M, Jagielski J. Functional properties of poly(tetrafluoroethylene) (PTFE) gasket working in nuclear reactor conditions. J Mol Struct 1157: 306-311 (2018)

[24] Ramani R, Kotresh T M, Shekar R I, Sanal F, Singh U K, Renjith R, Amarendra G. Positronium probes free volume to identify para- and meta-aramid fibers and correlation with mechanical strength. Polymer 135: 39-49 (2018)

[25] Zhang M M, Yan H X, Yuan L X, Liu C. Effect of functionalized graphene oxide with hyperbranched POSS polymer on mechanical and dielectric properties of cyanate ester composites. RSC Adv 6(45): 38887-38896 (2016)

[26] Xing L X, Liu L, Huang Y D, Jiang D W, Jiang B, He J M. Enhanced interfacial properties of domestic aramid fiber-12 via high energy gamma ray irradiation. Comp Part B Eng 69: 50-57 (2015)

[27] Yuan J Y, Zhang Z Z, Yang M M, Li P L, Men X H, Liu W M. Graphene oxide-grafted hybrid-fabric composites with simultaneously improved mechanical and tribological properties. Tribol Lett 66: 28 (2018)

He joined Prof. Zhaozhu Zhang's group at Lanzhou Institute of Chemical Physics in 2012. His current research interests are focused on improving the tribological properties of the polymer composite coating, fabric reinforced composite, and studying the corresponding mechanism.

current research interests cover the tribology of composite materials, designing functional surfaces with special wetting behavior, and engineering coatings for drag-reduction. He has published over 150 journal papers and gained a number of national scientific awards. 